\title{
Understanding Consumers' Satisfaction and Loyalty: A Comparative Study of Services in India and Japan
}

\author{
Yoshie Nagashima $^{1, *}$, Naoki Nagashima ${ }^{2}$ \\ ${ }^{1}$ Faculty of Business Administration, Daito Bunka University, Japan \\ ${ }^{2}$ Faculty of Business Administration, Toyo University, Japan
}

Copyright@2017 by authors, all rights reserved. Authors agree that this article remains permanently open access under the terms of the Creative Commons Attribution License 4.0 International License

\begin{abstract}
The main objective of this paper is to illustrate validity of Consumer Satisfaction (CS) and Loyalty research as an effective complement to conducting ethnographic research. More and more companies who enter foreign markets increasingly rely on ethnographic research. However, in conducting ethnographic research, field workers need to attach themselves to the local communities, and this type of research is highly elaborate and complex. This paper suggests that CS and Loyalty research is effective in understanding consumers' traits, and provides valid insight in a short period of time. In our study, we take up eat-out experiences at restaurants and coffee shop chains. Our findings on urban middle-class consumers in two Asian countries, India and Japan, indicate 1) "Expectancy-disconfirmation model" and "Loyalty ladder" do not apply to Indian consumers, while they apply well to the Japanese counterparts, 2) different attributes are important in terms of impact on CS between the two countries, and 3) an improved CS is more likely to lead to positive word of mouth than repeated usage of the service in India, and the reverse holds for Japan. The findings from this study indicate validity of the method and framework of research conducted.
\end{abstract}

Keywords Consumer Behavior, Marketing, Service Business, India, Consumer Satisfaction, Loyalty

\section{Introduction}

Today an increasing number of companies are entering and conducting businesses in emerging markets. Service businesses, especially B to C companies, usually have a series of contact points with customers. They are called "Service-encounters" where "Moments of truth" can be realized [1-3]. Therefore, it is essential for service business firms to understand cognitive and emotional characteristics of targeted consumers. They include satisfaction with and loyalty to the concerning services. Consumers in the emerging markets may react differently to the services provided in the companies' homeland: developed countries for many of these multinationals. Thus, these service business firms need to adjust marketing strategies in accordance with the local consumers' traits.

It is usually assumed that it takes time to understand consumers' traits. If the business is about manufacturing, consumers' responses will mainly be to the products. However, in the area of service, delivering processes and their environment are often crucial upon consumers' evaluation. For instance, a coffee shop chain can test the taste of their coffee in advance. However, services provided by shop staff, ambience at the shop, and other attributes related to the service will be highly contextual. In addition, it is not easy to set up the similar environment constantly.

Companies that aim to expand their business by entering a foreign market tend to compare the new market to that of their homeland's, which they understand the most. Accordingly, this study attempts to understand consumers in a short period of time, by comparing and analyzing eat-out experiences of Indian and Japanese consumers. It would be easier for companies in developed countries to understand the research results in comparison to their homeland consumers. Therefore, we compare the results of Indian consumers to the Japanese counterparts. The framework that we propose in this study is not an alternative to a deep ethnographic research, but it should be able to provide valid insight in a short period of time related to forming marketing strategy.

\section{Preceding Studies}

The approach mentioned in the previous section is based on the idea that clarifying the traits of consumers in a specific area of consumption should be best attained by examining consumer satisfaction (CS, hereafter) and loyalty. Hence, this section explains preceding studies with respect to CS and loyalty that we have adopted either theoretically or 
methodologically. First, we review studies on CS and focus on two topics that this study is closely associated with: 1) relationship between overall evaluation and partial evaluations of CS, and 2) roles of expectations.

As for the relationship between overall evaluation and partial evaluations, Mittal, Ross, and Baldasare (1998) and Nagashima, Nag, and Nagashima (2015) exemplify and explore quantitatively[4,5]. These studies find asymmetric and non-linear nature of the relationship concerned [4,5]. On the other hand, Stauss and Weinlich (1997) and Nagashima (2009) conduct qualitative analyses to identify different traits of each phase as the service process proceeds [6,7]. Stauss and Weinlich propose the idea of "Minimum-requirement factor" and "Value-enhancing factor," the notions which we apply in this study.

Expectations in the context of service evaluation have been extensively examined. Among them are Grönroos (1984) and Parasuraman, Zeithaml, and Berry (1988) [8,9]. The former emphasizes the importance of process and results of services, and the latter proposes the representative framework of service evaluation, "SERVQUAL." Both studies regard that each of the attributes is evaluated in comparison to the expectation given to it. They argue that the attributes influence or aggregately form overall evaluation. This concept is widely known as "Expectancy-disconfirmation model of satisfaction." Considering these preceding studies, we attempt to classify attributes into "Minimum-requirement factors" or "Valueenhancing factors" introduced in Stauss and Weinlich (1997) [6]. Regarding the roles of expectation, we empirically test its effect on CS.

There are arguments on the conceptual differences between the notion of CS and overall service evaluation. Yet, representative studies which focus on empirical aspects support the use of single dimensional overall evaluation as the surrogate for CS $[4,10,11]$. Following this, we regard overall service evaluation as CS.

Next, we look into preceding studies on loyalty. How customer loyalty is established is equally important as the structure of CS to understand consumers' traits. Recent studies tend to conceptualize loyalty both from behavioral and attitudinal aspects. Dick and Basu (1994) [12], for example, proposes a framework with the dimensions of repeated purchases and relative attitudes. Repeated purchases represent patronage, which is the behavioral aspect. On the other hand, relative attitudes stand for psychological tendency or attachment, which is the attitudinal aspect. Consequently Dick and Basu propose four categories: true loyalty, spurious loyalty, latent loyalty, and no loyalty.

The behavioral aspect of loyalty can simply be measured by repeated purchases. On the other hand, the attitudinal aspect is not simple to measure, yet there are several ways to operationalize the construct. Representative measures that are operationalized include 1) intention to purchase again, 2) feeling attached (“Attachment”), 3) intention to recommend it to someone else. Among them, Baron, Conway, and Warnaby (2010) [13] regards "Attachment" as the most important as attitudinal aspect of loyalty. This is because this psychological tendency does, in due course, lead to future usage and positive word of mouth (WOM). Today the attitudinal loyalty is often called "Commitment" meaning "Intention to Repurchase," "Attachment," or "Intention to Recommend."

With respect to the order of loyalty, Christopher, Payne, and Ballantyne (2002) [14] proposes the idea "Loyalty ladder," asserting that a customer can go up to "Client," "Supporter," "Advocate," and finally to "Partner." They explain that "Client" is a repeat purchaser, "Supporter" feels attached, and "Advocate" spreads out positive WOM. Therefore, according to Christopher et al., behavioral loyalty is still at an undeveloped stage that should be developed into "Supporter" with attachment, and then into "Advocate" with an intention to recommend.

\section{Basic Ideas and Methods}

We propose the following framework which consists of four phases, to quickly understand consumers' traits. In this study, consumers' traits are examined in line with each of the business fields. We take up quick service restaurants (QSRs, hereafter) and coffee chains in India and Japan.

Phase 1: Overall Distribution of CS and Loyalty

Phase 2: Influential Attributes of CS and the Possible Structure

Phase 3: Roles of Expectations

Phase 4: Contributions of CS to Loyalty

Phase 1 is about understanding general distributions of CS and loyalty to service. Distribution of CS and observed loyalty are examined here. This observation indicates how well the service concerned is being accepted by consumers. Phase 2 examines attributes that influence CS, which may be different by country and by service type. Phase 3 is about how consumers' expectations influence service evaluation. This analysis will be closely linked to a company's communication strategy, such as advertisement. Phase 4 is to analyze relationship between CS and loyalty. The findings should give us implications as to how much we should invest in improving CS in relation to its linkage to loyalty.

Data were collected by questionnaire surveys. The outline of surveys is summarized in Table 1. First, respondents screened in the pre-survey proceeded to the main parts of the survey. The respondents were required to have experienced the service in the previous 3 months, and remembered the experiences well. They also had to be willing to describe their experiences. 
Table 1. Questionnaire Surveys Conducted in India and Japan

\begin{tabular}{|c|c|c|}
\hline & India & Japan \\
\hline Effective samples & $\mathrm{n}=788$ & $\mathrm{n}=751$ \\
\hline Respondents: & \multirow{2}{*}{18 years old and above } & \multirow{2}{*}{ From 20 to 69 years old } \\
\hline age & & \\
\hline area & Residents of Delhi, Mumbai, and Chennai & Residents of Tokyo, Osaka, and Nagoya \\
\hline $\begin{array}{l}\text { income bracket, social } \\
\text { economic class }\end{array}$ & $\begin{array}{l}\text { Household annual income of 200,000 INR or above and also } \\
\text { classified as A or B in terms of SEC (Social Economic Class) }\end{array}$ & $\begin{array}{l}\text { No restrictions (Household annual income of } 3 \text { to } 10 \\
\text { million yen account for } 65 \% \text { of the effective samples) }\end{array}$ \\
\hline experience & \multicolumn{2}{|c|}{$\begin{array}{l}\text { Have eat-out experiences at a QSR or a coffee shop within the last } 3 \text { months, which he/she remembers well and are } \\
\text { willing to be asked about }\end{array}$} \\
\hline Period & February through March, 2015 & October through November, 2015 \\
\hline Method & $\begin{array}{l}\text { On-line survey answered by monitors managed by InfoBridge } \\
\text { Marketing \& Promotions Co., Ltd. }\end{array}$ & $\begin{array}{l}\text { On-line survey answered by monitors managed by MS } \\
\text { \& Consulting }\end{array}$ \\
\hline Questions & \multicolumn{2}{|c|}{$\begin{array}{l}\text { - } \quad \text { Demographic information which includes gender, age, residential area (city), and household annual income } \\
\text { - } \\
\text { - }\end{array}$} \\
\hline
\end{tabular}

Respondents of the survey in India live in the urban area of Delhi, Mumbai, or Chennai; the sample numbers of which are 255, 265, and 268 respectively. Out of 788 respondents in total, 454 answered about their experiences at QSRs, and 334 about those at coffee shops. 135 respondents answered about KFC, 131 about McDonald's, 223 about Café Coffee Day, and 40 about Costa Coffee.

As for the survey in Japan, respondents are from Tokyo, Osaka, or Nagoya, the sample numbers of which are 297, 228, and 226 respectively. In Japan, food chains are usually categorized into "fast-food chain" and "family restaurant chain." So these names were used in the questionnaires. As a result, 250 answered about fast-food chain, 250 about family restaurants, and 251 about coffee shops. The first two categories are considered equivalent to QSRs in India. 183 respondents answered about McDonald's, 108 about GUSTO (Skylark group), 130 about Starbucks Coffee, and 57 about Doutor Coffee.

\section{Results}

\subsection{Phase 1: Overall CS and Loyalty}

Figure 1 shows simple distributions of CS for both QSRs and coffee shops in India and Japan. CS is considered to include any influential element from taste of food/drink, cost, time taken, comfort at the shop, etc., and asked in the questionnaires accordingly. The scale is from zero (Poor) to ten (Excellent), while five represents neutral (Neither good nor bad). At a glance, consumers in India tend to evaluate shops more favorably than their Japanese counterparts. The difference between the two countries is greater for evaluations on QSRs than on coffee shops. If we take a close look at them, consumers in India tend to evaluate QSRs higher than coffee shops. On the other hand, the reverse tendency is observed with the consumers in Japan.
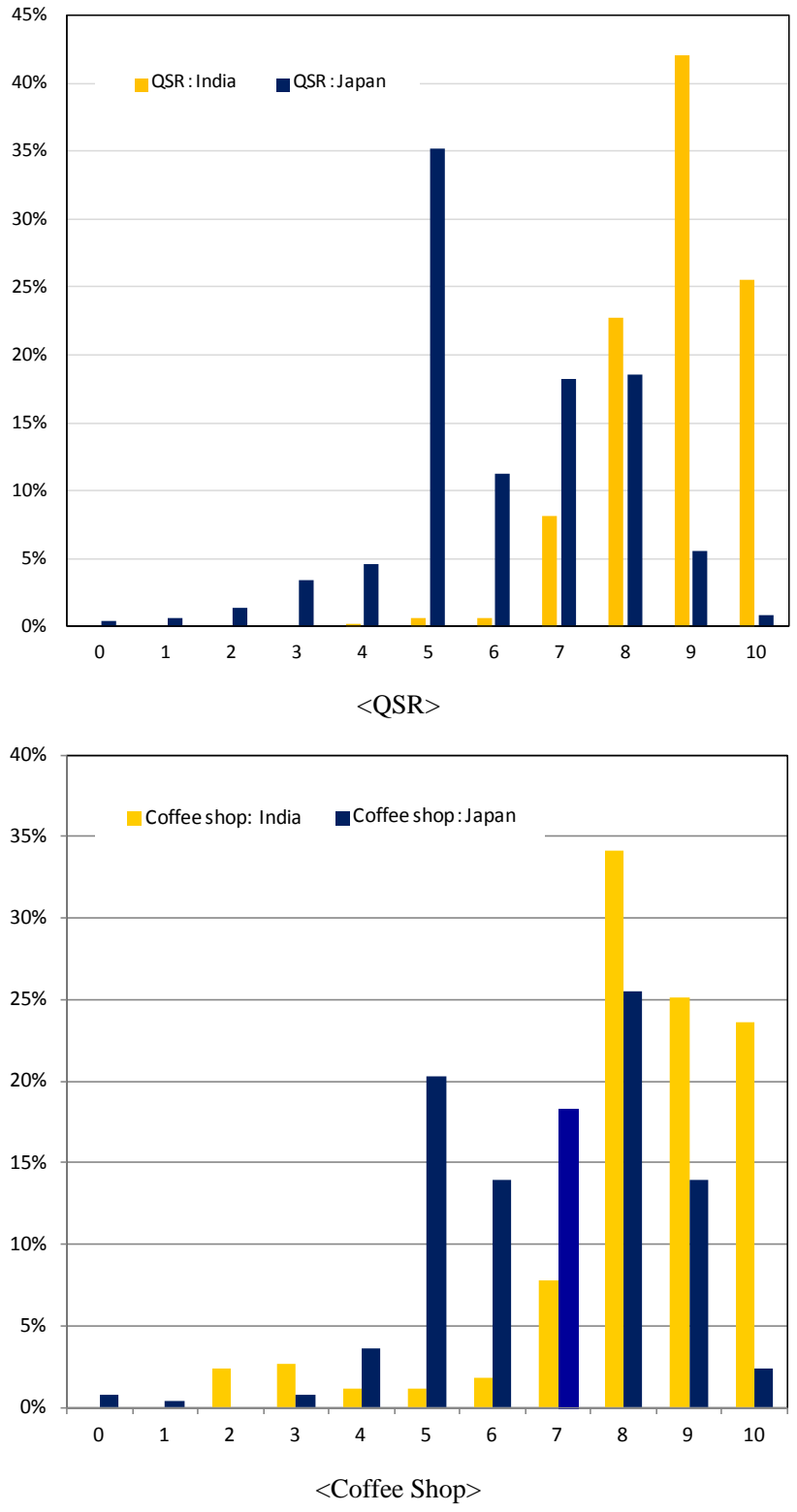

Figure 1. Distributions of CS Evaluation 
Other observations about overall CS are its differences with respect to residential areas, gender, age, and household income. While in Japan, no difference has been observed with these attributes, in India, the older or the wealthier they are, the severer their evaluations become. Also, residents in Delhi tend to rate their eat-out experiences more highly than those in Mumbai or Chennai. The average of CS is 9.31 (Delhi), 8.47 (Chennai), and 7.97 (Mumbai), with the difference statistically significant by ANOVA F-test (F_value=71.426, df1=2, df2=785, p-value $=0.000$ ).

Following the overall distribution of CS evaluation, we present distribution of loyalty of both countries. Table 2 introduces matrices of the relationship between behavioral and attitudinal loyalty, as proposed by Dick and Basu (1994). More specifically, it shows the relations between frequency of visit and attachment felt. This reveals a sharp contrast between consumers of the two countries. Out of those who exhibit behavioral loyalty, more than two-thirds of consumers in India feel attached, while most of the Japanese consumers are classified as "Spurious loyalty" without attachment. In addition, in India, about $20 \%$ respondents are showing "Latent loyalty," while in Japan this ratio is less than $3 \%$. Since "Latent loyalty" can grow to "True loyalty" if constraints, such as budget or time, are mitigated, we can assume much more potential for expansion in India than in Japan.

Original form proposed by Dick \& Basu (1994) is as follows.

\begin{tabular}{c|cc|c|}
\multicolumn{1}{c}{} & \multicolumn{2}{c}{ Relative Attitude } \\
\cline { 3 - 4 } \multicolumn{1}{c|}{} & High & Low \\
\cline { 2 - 4 } & Repeated \\
\cline { 2 - 4 } Purchase & High & True loyalty & Spurious loyalty \\
\cline { 2 - 4 } & Low & Latent loyalty & No loyalty \\
\cline { 2 - 4 } & &
\end{tabular}

\subsection{Phase 2: Elements Influencing CS}

In this section, we then discuss the elements of CS. Figure 2 indicates relations between overall CS and partial evaluations; evaluations on elements. Correlation does not necessarily mean causation, but it is natural in this context, to predict each element has certain influence on CS. Thus here, we regard correlations as influence of elements on CS. This interpretation is reinforced by the fact that these elements have been extracted beforehand as being influential on CS by consumer interviews. The details of qualitative research, including laddering technique, are introduced in Nagashima (2009) [7].

Regarding QSRs, in India "Reasonability of pricing” and "Location" seem to be the most important in the sense that these elements are strongly correlated with CS. Meanwhile in Japan, "Customer service by shop staff," "Taste of food/drink," and "Cleanliness of the shop" are more important. We also observe that in India differences among elements are smaller, and more elements show smaller correlation with CS, compared to Japan. Considering the fact that consumers in India tend to show higher overall CS, the mechanism of improving CS seems to be more difficult to explain. As for coffee shops, the differences between the two countries are not as large as for QSRs', except that "Location" and price factors such as "Reasonability of pricing" have more influence on CS in India.

Are there any possible structures among elements? In this regard, we examine 1) the possibilities of extracting bundles of elements, and 2) the influence of elements on CS with asymmetric effects. To analyze the first possibilities, we apply factor analysis, and the results can be summarized as follows.

The patterns of factor loadings are similar for both country's QSRs as well as Japan's coffee shops. The first factor can be interpreted as an overall experience, and the second factor as perceived price cost. For India's coffee shops, only one factor is extracted, resulting in a failure as factor analysis. But if we look at the ratio explained by each factor, the second factor of India's QSRs is small, and close to collapsing. Therefore, extracting meaningful bundles is difficult for both types of services in India.

Table 2. Loyalty in the form of Dick \& Basu

$<$ QSR $>$

\begin{tabular}{|c|c|c|c|c|c|c|}
\hline \multicolumn{6}{|c|}{ e Shop> } & \multirow{3}{*}{ Total } \\
\hline & & \multicolumn{4}{|c|}{$\begin{array}{c}\text { Attitude } \\
\text { (Attachment) }\end{array}$} & \\
\hline & & & gh & & ow & \\
\hline \multirow{2}{*}{$\begin{array}{c}\text { Behavior } \\
\text { (Repeated } \\
\text { Purchse) }\end{array}$} & High & $\begin{array}{l}\text { India } \\
\text { Japar }\end{array}$ & $\begin{array}{c}43.7 \% \\
7.2 \%\end{array}$ & $\begin{array}{l}\text { India } \\
\text { Japan }\end{array}$ & $\begin{array}{l}16.5 \% \\
32.3 \%\end{array}$ & $\begin{array}{l}60.2 \% \\
39.4 \%\end{array}$ \\
\hline & Low & $\begin{array}{l}\text { India } \\
\text { Japar }\end{array}$ & $\begin{array}{r}19.5 \% \\
2.8 \%\end{array}$ & $\begin{array}{l}\text { India } \\
\text { Japan }\end{array}$ & $\begin{array}{l}20.4 \% \\
57.8 \%\end{array}$ & $\begin{array}{l}39.8 \% \\
60.6 \%\end{array}$ \\
\hline & Total & $\begin{array}{l}\text { India } \\
\text { Japal }\end{array}$ & $\begin{array}{l}63.2 \% \\
10.0 \%\end{array}$ & $\begin{array}{l}\text { India } \\
\text { Japar }\end{array}$ & $\begin{array}{l}36.8 \% \\
90.0 \%\end{array}$ & $\begin{array}{l}100 \% \\
100 \%\end{array}$ \\
\hline
\end{tabular}

Notes:

Behavior (Repeated Purchase):

Yes=Visited the same shop six times or more in the last 12 months. No=Visited it up to five times in the same period

Attitude (Attachment):

Yes=Feel attached definitely (Five out of five point scale)

No=One-Four out of five point scale ("Somewhat yes" is classified as "No"). 


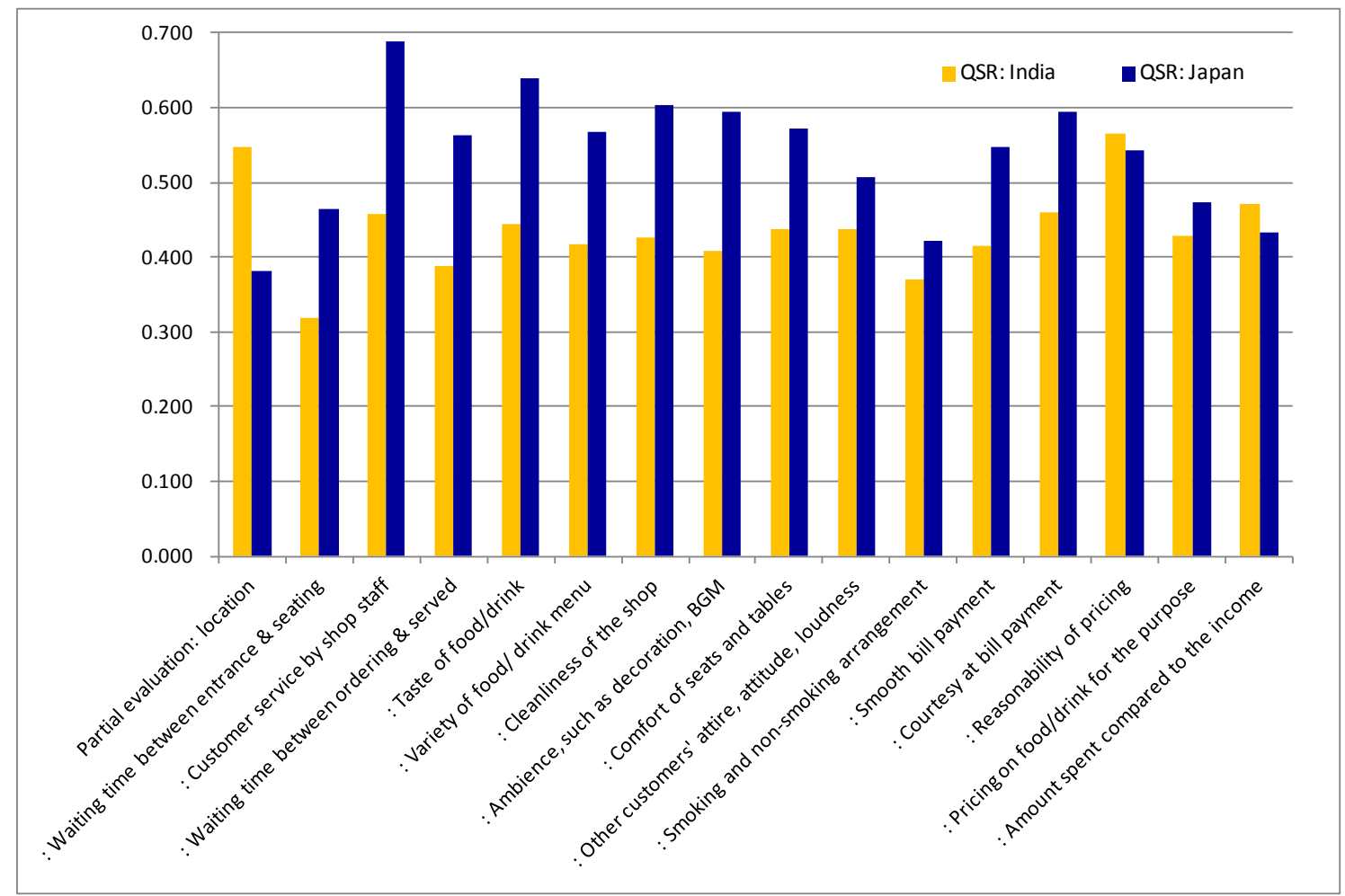

$<\mathrm{QSR}>$

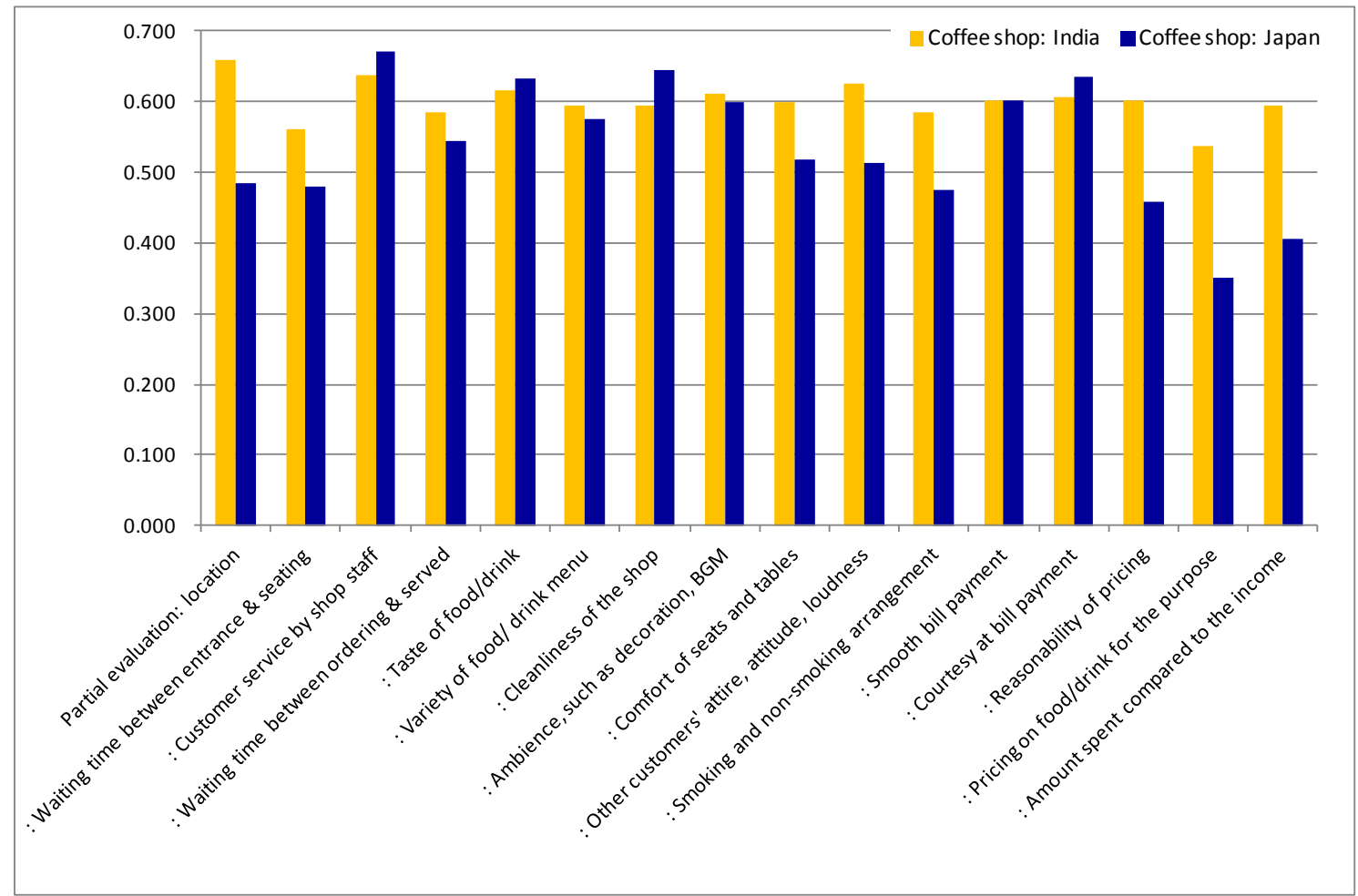

$<$ Coffee Shop $>$

Note: Vertical axes of both figures denote Pearson's correlation coefficient between CS and evaluations on elements (partial evaluations).

Figure 2. Correlation between elements and overall CS 
With respect to the second purpose of this phase, analyzing "Asymmetric effects" of elements on CS, we attempt to divide elements into "Minimum-requirement" and "Value-enhancing" factors, as proposed by Stauss and Weinlich (1977) [6]. The former causes to deteriorate CS if it falls short of the neutral point, and the latter causes to improve CS if it exceeds neutral. This classification is attempted by measuring its correlation with CS when the partial evaluation is lower than neutral and when higher than neutral. If the item indicates stronger correlation with CS when it is lower than neutral, it is implied to be a "Minimum-requirement factor." If it does when it is higher than neutral, it is a "Value-enhancing factor."

This division between elements works well for consumers in Japan, but does not work sufficiently for those in India. This is probably due to skewness in the distributions of partial evaluations, as well as overall CS, shown by Indian consumers. Most of the Indian consumers evaluate elements more favorably than neutral. Also, all items indicate correlations with CS that are statistically significant at $1 \%$ significance level. This should be causing most elements to be classified into "Value-enhancing factors," making it difficult to find "Minimum-requirement factors."

Here, we introduce the results of element-level analysis for Japanese consumers. "Minimum-requirement factors" are customer service by shop staff, waiting time between ordering and serving, taste of food/drink, and reasonability of pricing. On the other hand, "Value-enhancing factors" are cleanliness of the shop, ambience such as decoration, and BGM. Comfort of the seat and table, smoking and non-smoking arrangement, smooth bill payment, and courtesy at bill payment are also included in "Value-enhancing factors." Also, customer service by shop staff, cleanliness of the shop, and reasonability of pricing are important in both ways. For Indian consumers, all items but smooth bill payment are "Value-enhancing factors" probably because of the reasons explained above.

\subsection{Phase 3: Roles of Expectations}

We then address the role of expectations. In the surveys, we asked the respondents on 16 elements whether they felt better than expected, about the same, worse than expected, or had no expectation beforehand. Here, we compare consumers of both countries from two perspectives: 1) whether expectations by customers become more proactive and accurate as frequency of visits increases, and 2) whether CS depends on the excess over expectations as indicated by "Expectancy-disconfirmation" framework [8, 9].

Table 3. Number of elements correctly expected and not expected

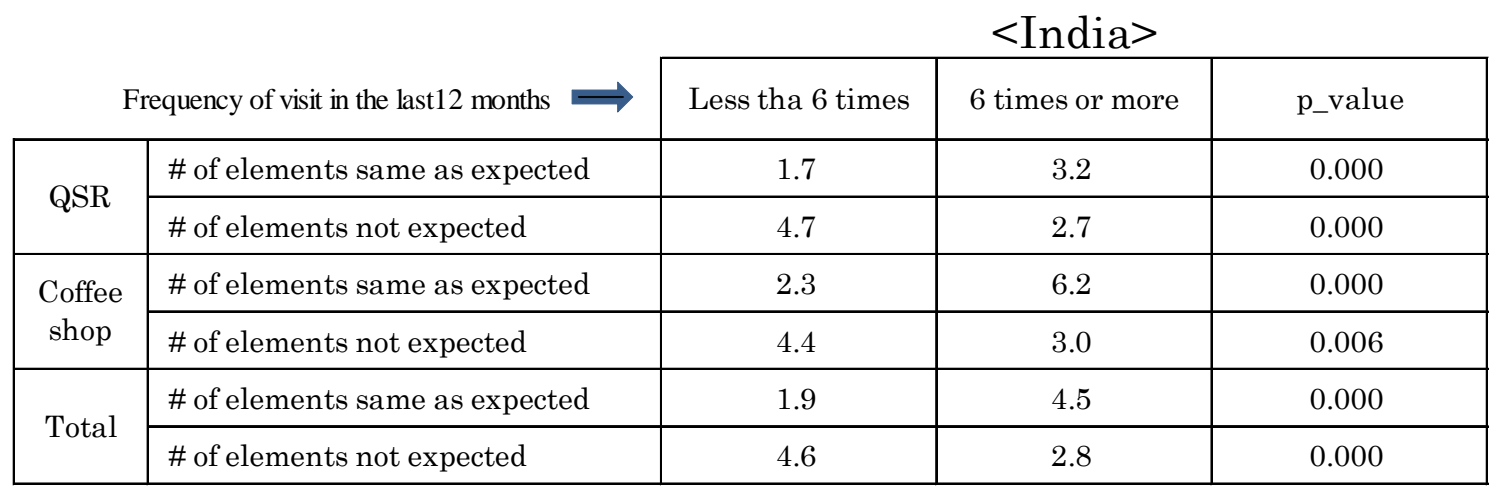

\begin{tabular}{|c|c|c|c|c|}
\hline \multirow{2}{*}{\multicolumn{2}{|c|}{ Frequency of visit in the last12 months $\longrightarrow$}} & \multicolumn{3}{|c|}{$<$ Japan > } \\
\hline & & Less tha 6 times & 6 times or more & p_value \\
\hline \multirow{2}{*}{ QSR } & \# of elements same as expected & 10.1 & 9.9 & 0.725 \\
\hline & \# of elements not expected & 0.9 & 0.8 & 0.668 \\
\hline \multirow{2}{*}{$\begin{array}{c}\text { Coffee } \\
\text { shop }\end{array}$} & \# of elements same as expected & 10.5 & 9.5 & 0.066 \\
\hline & \# of elements not expected & 0.7 & 1.0 & 0.318 \\
\hline \multirow{2}{*}{ Total } & \# of elements same as expected & 10.2 & 9.8 & 0.175 \\
\hline & \# of elements not expected & 0.8 & 0.9 & 0.834 \\
\hline
\end{tabular}

Notes:

1. “\#” in the table means "the number.” (This also applies to Table 3)

2. Frequency of visit is based on the specific shop that the respondent is answering about.

3. Indicated numbers are out of 16 elements. 
As Table 3 shows, consumers in India are following their rationale, i.e., as frequency of visit rises, the number of elements that are correctly expected increases. In the case of consumers in Japan, they do not show any meaningful difference which relates to frequency of visit. This contrast reminds us of complex and whimsical minds and/or behaviors observed in slow-growing mature economies.

However, with respect to the conformity to "Expectancy-disconfirmation model," Indian consumers seem to be more complex as shown in Table 4. While this model applies to Japanese consumers regardless of the frequency of visit, it does not apply at all to Indian consumers. In many cases, even the signs of correlation coefficients are opposite to those theoretically assumed. In this sense, excess over expectations is not a meaningful criterion to measure CS or an effective way to improve it in India.

\subsection{Phase 4: Contributions of CS to Loyalty}

The purpose of this section is to clarify the relationship between CS and loyalty. First, we illustrate it in Figure 3. Here, the CS levels are divided into four ranks; Low, Low-middle, High-middle, and High, allocated so that each category has a similar sample size. According to this classification, the ratios of obtained loyalty are being displayed. Loyalty is expressed here as being four-fold; 1 )
Behavioral loyalty (Repeated visit), 2) Intention to revisit, 3) Attachment, and 4) Intention to recommend. 2) through 4) are operationalized forms of attitudinal loyalty.

Figure 3 clearly illustrates the differences and similarities of consumers in India and Japan. With regard to the similarity, while the relations between CS and behavioral loyalty are rather ambiguous, those between CS and attitudinal loyalty are clear. Consumers of both countries tend to show more attitudinal loyalty as the CS level improves. Regarding the differences, attachment and intention to recommend are easier to obtain in India, even when CS levels are not very high. In Japan, it is difficult, even if CS is very high. However, they tend to be more loyal in terms of intention to revisit. The relationship of this aspect in Japan are clearer than in India.

\section{Discussion}

\subsection{Summary of Findings}

We have proposed a patterned research methodology consisting of 4 phases. Applying this framework, we have found the following about middle-class consumers in India in the field of food chains.

Table 4. Empirical results of "Expectancy-disconfirmation model"

-- Correlation coefficient with CS --

\begin{tabular}{|c|c|c|c|c|c|}
\hline & \multicolumn{2}{|c|}{$<$ India $>$} & \multicolumn{2}{|c|}{$<$ Japan $>$} \\
\hline & & Less tha 6 times & 6 times or more & Less tha 6 times & 6 times or more \\
\hline \multirow{3}{*}{ QSR } & (1) \# of elements above expectation & & & $0.317^{* *}$ & $0.209 * *$ \\
\hline & (2) \# of elements below expectation & $0.388^{* *}$ & $0.182^{* *}$ & $-0.450^{* *}$ & $-0.283^{* *}$ \\
\hline & (3) \# of elements (1) - (2) & $-0.248^{* *}$ & & $0.493^{* *}$ & $0.294^{* *}$ \\
\hline \multirow{3}{*}{$\begin{array}{l}\text { Coffee } \\
\text { shop }\end{array}$} & (1) \# of elements above expectation & & & $0.234^{* *}$ & $0.254^{* *}$ \\
\hline & (2) \# of elements below expectation & $0.175^{*}$ & & $-0.410^{* *}$ & $-0.442^{* *}$ \\
\hline & (3) \# of elements (1) - (2) & $-0.173^{*}$ & & $0.389^{* *}$ & $0.381^{* *}$ \\
\hline \multirow{3}{*}{ Total } & (1) \# of elements above expectation & & $0.122^{* *}$ & $0.287^{* *}$ & $0.234^{* *}$ \\
\hline & (2) \# of elements below expectation & $0.244^{* *}$ & $0.114^{*}$ & $-0.439 * *$ & $-0.349^{* *}$ \\
\hline & (3) \# of elements (1) - (2) & $-0.167 * *$ & & $0.459^{* *}$ & $0.337^{* *}$ \\
\hline
\end{tabular}

Notes:

1. “*” denotes that the correlation is statistically significant at the $5 \%$ significance level (both-sided). “*** same as above at the $1 \%$ level 2. Shaded cells indicate that the result shown contradicts "Expectancy-disconfirmation-model." Blank cells indicate no statistically significant correlation coefficients obtained. 

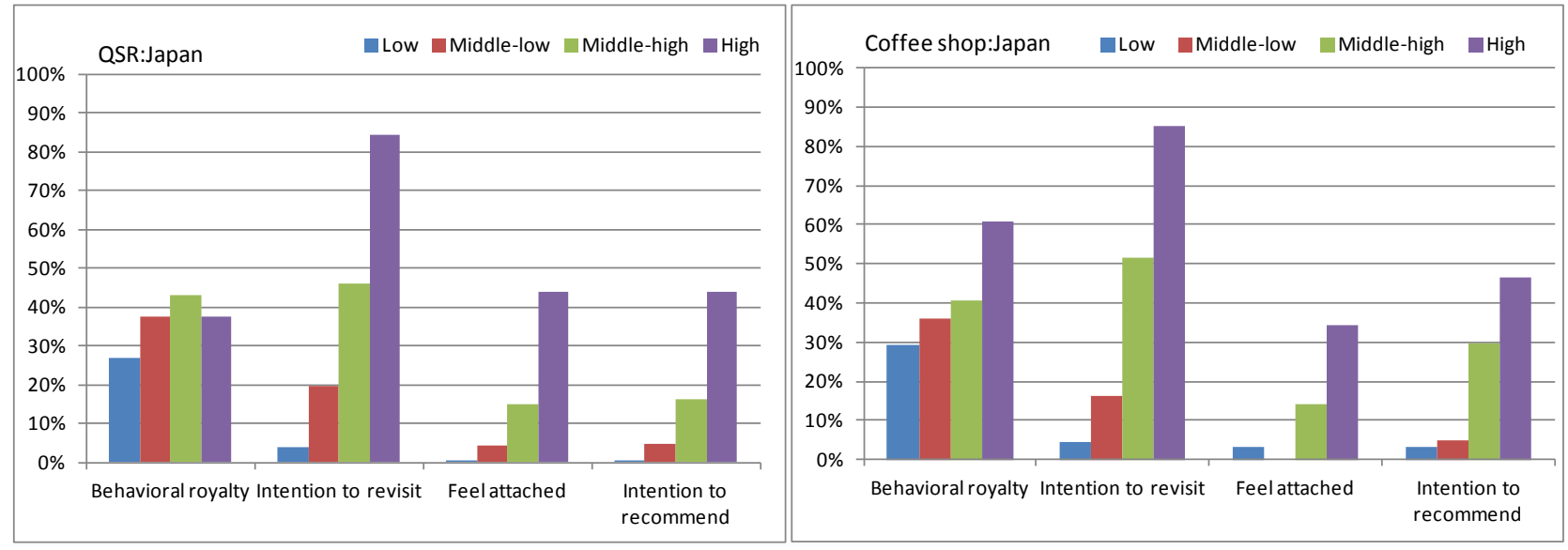

$\underline{\text { India }}$

$<$ QSR $>$

$<$ Coffee Shop $>$
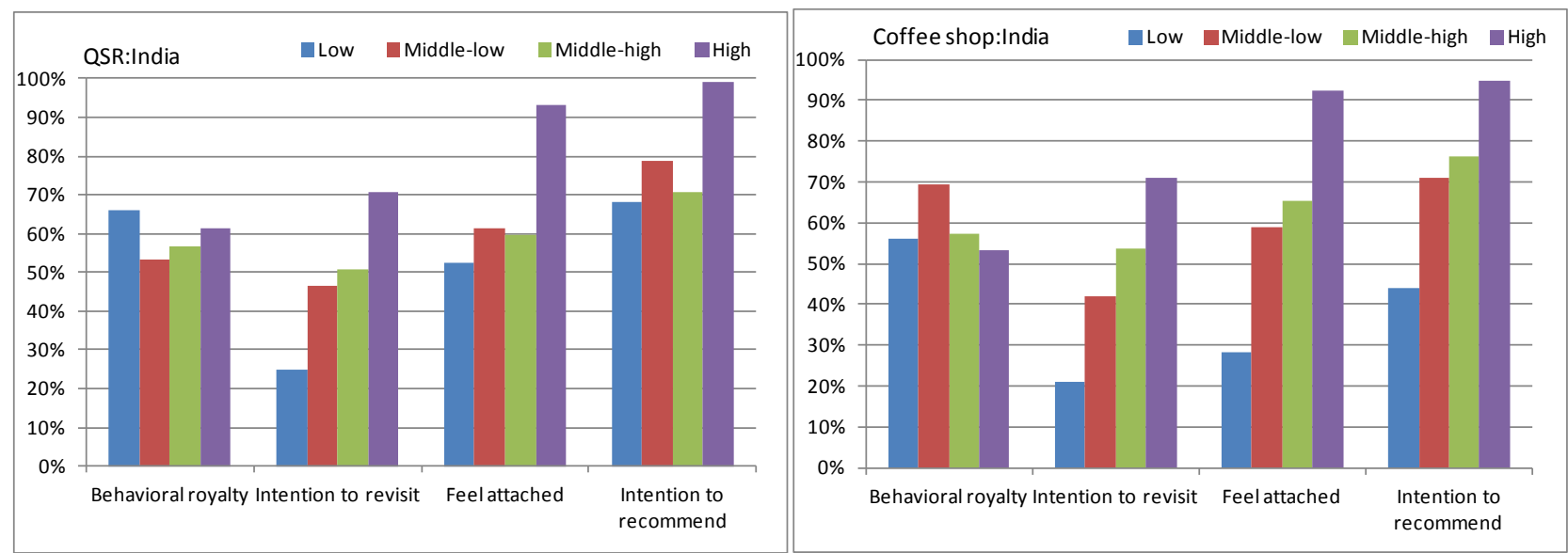

Note: 1. Ranks of CS for India are, Low: 0-7, Low-middle: 8, High-middle: 9, High: 10.

Ranks of CS for Japan are, Low: 0-5, Low-middle: 6-7, High-middle: 8, High: 9-10.

2. Vertical axes denote the ratio of respondents who indicated the respective aspect of loyalty, where behavioral loyalty represents "Frequency of visits" is 6 times or more in the last 12 months.

3. Differences in the loyalty level by the differences in the CS levels are tested, where the null hypothesis is "the loyalty levels are the same among four ranks of CS levels.” Obtained p values by ANOVA F-tests are as follows.

\begin{tabular}{|c|c|c|c|c|c|c|c|c|}
\hline & \multicolumn{4}{|c|}{$<$ India $>$} & \multicolumn{4}{|c|}{$<$ Japan > } \\
\hline & $\begin{array}{l}\text { Behavioral } \\
\text { royalty }\end{array}$ & $\begin{array}{l}\text { Intention to } \\
\text { revisit }\end{array}$ & Attachment & $\begin{array}{l}\text { Intention to } \\
\text { recommend }\end{array}$ & $\begin{array}{l}\text { Behavioral } \\
\text { royalty }\end{array}$ & $\begin{array}{l}\text { Intention to } \\
\text { revisit }\end{array}$ & Attachment & $\begin{array}{l}\text { Intention to } \\
\text { recommend }\end{array}$ \\
\hline QSR & 0.446 & 0.000 & 0.000 & 0.000 & 0.021 & 0.000 & 0.000 & 0.000 \\
\hline Coffee shop & 0.099 & 0.000 & 0.000 & 0.000 & 0.010 & 0.000 & 0.000 & 0.000 \\
\hline
\end{tabular}

Figure 3. Differences in loyalty levels by the differences in CS levels

Phase 1: Overall CS is higher in India than in Japan. The differences with QSRs are greater than that with coffee shops; in India, coffee shop visitors are wealthier on average. In addition, wealthier people tend to rate more critically in India, making the difference from the Japanese counterparts smaller. With respect to the distribution of loyalty, the ratio of "Latent loyalty" is also large in India, indicating great potential for growth in the market. In contrast, a considerable ratio of consumers in Japan show "Spurious loyalty," that poses a threat of brand-switching even by repeated customers.

Phase 2: With regard to the influence of elements on CS, location and reasonability of pricing are more important in India than in Japan. This is more conspicuous for QSRs, while such difference is smaller for coffee shops. In addition, in India, 
CS is hardly decomposed to meaningful bundles of elements. Also, it is difficult to specify each element as to whether it is a "Minimumrequirement" or a "Value-enhancing" factor.

Phase 3: Indian consumers do not follow the "Expectancy-disconfirmation model." In most cases, the empirical results have turned out to contradict the theory. On the other hand, this theory perfectly applies to the consumers in Japan.

Phase 4: In India, a moderate CS level can lead to "Attachment" and "Intention to recommend." Additionally, when a consumer is a repeated user, it is very rare for him/her to become a "Detractor" even if his/her last experience was not satisfactory. In contrast, consumers in Japan tend to indicate "Intention to revisit" if they are satisfied, but even a high CS level hardly links to "Attachment" or "Intention to recommend." Furthermore, repeated usage is far from a satisfactory condition for "Attachment" or "Intention to recommend."

\subsection{Implications}

In this section, we will discuss the academic implications first. As we observed in Phase 3, "Expectancydisconfirmation model” applies to consumers in Japan, but not to those in India. In Japan, it is often said that a service provider needs to control customers' expectations so as not to be excessive. This is because a high expectation often leads to a letdown, resulting in an overall low evaluation of the service. However, in India, a high expectation itself tends to generate a favorable evaluation. This may imply the effectiveness of advertisement by media. This tendency could be generalized to other fields of services in emerging markets.

"Loyalty ladder" by Christopher et al. (2002) [14] proposes the hierarchical order of loyalty, i.e. from "Customer," "Client (Heavy user)," "Supporter (Feeling attached)" to "Advocate (Promoter)." However, this order does not seem to apply in India. This is inferred by Phase 4; CS is more likely to contribute to "Attachment" and "Intention to recommend" than to "Intention to revisit" or "Frequent visits." Figure 4 illustrates this. In India, "Client" appears to be a satisfactory condition for "Supporter" and "Advocate," implying that the order should be from "Customer" to "Supporter and Advocate" simultaneously, and then to "Client." This prediction is reinforced by the fact that considerable number of people show "Latent loyalty" with attachment but without repeated purchase (Table 2). In Japan, on the other hand, the order proposed by "Loyalty ladder" seems to hold, although the path from "Client" to "Supporter" or "Advocate" is very narrow. "Expectancy-disconfirmation model" and "Loyalty ladder" are theories built on phenomena in developed economies.
However, we should rethink their applicability in the face of different features of emerging markets.

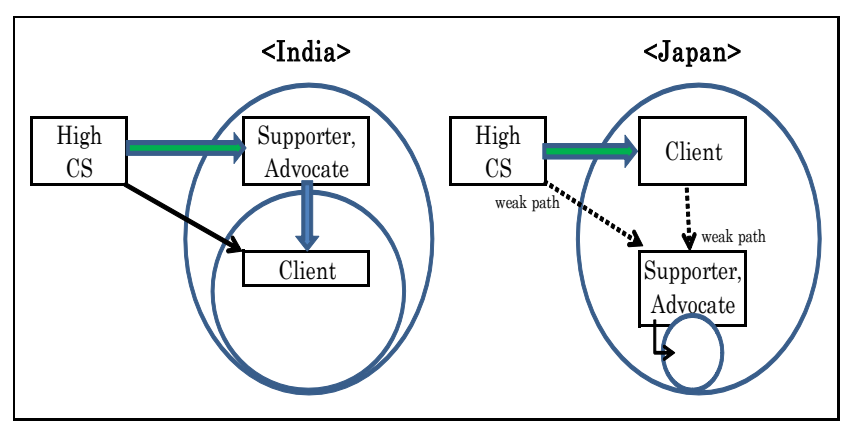

Source: Authors' construction

Figure 4. Order of loyalty revisited

We then discuss business implications. First of all, the proposed framework of 4-phase patterned analysis is helpful in understanding the traits of targeted consumers. For instance, we now know the impacts on CS are different among attributes and between the two countries in Asia. This knowledge suggests how we should prioritize investment in marketing activities. In addition, unlike in Japan, raising consumers' expectations is an effective strategy in India. This suggests specific advertisement campaigns and strategies are to be rolled out in the Indian market. Furthermore, we know an improved CS tend to cause attachment and positive word of mouth in India, rather than repeated usage of the service. In this regard, 'introductory special offer' may be more effective than discount tickets for repeaters. The time span of the research conducted in this study is two months, and it is based on fairy simple multiple-choice oriented questionnaires. Moreover, the results are easy to interpret, thus this framework should be easily performed by businesses practitioners.

\subsection{Limitations}

There are issues that have not been made clear by the framework presented in this study. These are left for further research. The first would be the structure of CS in India. In Phase 2, we found that a series of elements are equally important to determine CS, in addition to the fact that "Location" and "Reasonability of pricing" are particularly important. Yet, we could not extract meaningful bundle of elements, nor priorities to focus on.

Second, facing the result of Phase 3 which indicates high expectations positively affect CS, what kind of expectations are desirable and how they are formed are still unknown. These issues will be the focus of future, probably, qualitative research.

Finally, it needs a thorough examination to clarify whether the framework we propose is applicable to other areas of services, such as retailers, educational services, financial services, healthcare, and so on. Although basic concepts will be applicable since CS and loyalty are crucial in any 
business field, some adjustment, such as deciding elements possibly influential on CS, might be needed. A possible approach is shown in Nagashima (2009) [7], which employs a qualitative research; a simplified version of "Repertory grid” procedure, including “Laddering” technique.

\subsection{Conclusion}

As service businesses develop in emerging economies, there is a growing need for understanding consumers. This study proposes a patterned analysis that enables quick understanding of targeted consumers.

In spite of issues left for future study, the framework, Phase 1-4, has proved to be useful in acquiring marketing implications. These implications include which specific attributes have greater impact on CS. In addition, we observe difference whether improved CS leads to an increase in the number of repeaters or positive word of mouth. These findings and implications suggest validity of Consumer Satisfaction (CS) and Loyalty research as an effective complement to conducting ethnographic research.

Furthermore, this study indicates that "Expectancydisconfirmation model" and "Loyalty ladder" do not apply for consumers in India, while they apply for the Japanese counterparts quite well. Namely, the theories built on phenomena in developed economies are not necessarily applicable, and often contradict the truth of emerging markets. We believe this should be regarded as an academic contribution by this study.

The ultimate goal of international service marketing, we believe, is for the firms to build relationship with consumers in the market concerned. In this regard, the first step would be to understand targeted consumers before market entry. We believe this study contributes to establishing the methodology, and be of help for business firms.

\section{REFERENCES}

[1] Norman, R. (1986). Service management: Strategy and leadership in service businesses. Wiley.

[2] Carlzon, J. \& Peters, T. (1987). Moments of truth. Cambridge,
MA: Ballinger.

[3] Grönroos, C. (1990). Service management and marketing: managing the moments of truth in service competition. Jossey-Bass.

[4] Mittal, V., Ross, W. T., \& Baldasare, P. M. (1998). The asymmetric impact of negative and positive attribute-level performance on overall satisfaction and repurchase intentions. Journal of marketing, 62, 33-47.

[5] Nagashima, N., Nag, B., \& Nagashima, Y. (2015). How Are Shopping Experiences Evaluated? A Methodological Proposal to Understand Consumers as Shoppers. Journal of Marketing Development and Competitiveness, 9(1), 115-128.

[6] Stauss, B. \& Weinlich, B. (1997). Process-oriented measurement of service quality: Applying the sequential incident technique. European Journal of Marketing, 31(1), 33-55.

[7] Nagashima, N. (2009). Transition of Evaluation Focus in Service Processes: Focusing on Non-face-to-face Services. Journal of Consumer Behavior, 16(1), 37-58.

[8] Grönroos, C. (1984). A Service Quality Model and its Marketing Implications. European Journal of Marketing, 18(4), 36-44.

[9] Parasuraman, A., Zeithaml, V. A., \& Berry, L. L. (1988). SERVQUAL: A Multiple-Item Scale for Measuring Consumer Perceptions of Service Quality. Journal of Retailing, 64(1), 12-40.

[10] Bitner, M. J \& Hubbert, A. (1994). Encounter Satisfaction Versus Overall Satisfaction Versus Quality: The Customer's Voice. In R. T. Rust \& R. L. Oliver (eds), Service Quality: New Directions in Theory and Practice, 72-94. Thousand Oaks, CA: Sage Publications.

[11] Spreng, R. A., MacKenzie, S. B., \& Olshavsky, R. W. (1996). A Reexamination of the Determinants of Consumer Satisfaction. Journal of Marketing, 60 (July): 15-32.

[12] Dick, A. S. \& Basu, K. (1994). Customer Loyalty: Towards an Integrated Conceptual Framework. Journal of the Academy of Marketing Science, 22 (2), 99-113.

[13] Baron, S., Conway, T., \& Warnaby, G. (2010). Relationship Marketing: A Consumer Experience Approach. Sage Publications.

[14] Christopher, M., Payne, A., \& Ballantyne, D. (2002). Relationship Marketing, Oxford: Butterworth-Heinemann. 